\title{
Establishment of standards for post-operative nursing care in patients with Percutaneous Nephrostomy tube $(\mathrm{PCN})$ insertion
}

\author{
Kamilia F. Abdel Fattah, Salah El- Din S. Abdel Hafez \& Hala M. Ghanem. \\ Supervisor in general operative theatre, Assiut Assistant University, Hospital, Assiut Egypt. \\ Professor of Urology, Faculty of Medicine, Assiut University Egypt. \\ Assistant Prof. of medical-surgical Nursing (Adult Nursing), Faculty of Nursing Egypt.
}

\begin{abstract}
Aim of the study:1] To assess nurses' knowledge and practice regarding percutaneous nephrostomy tube patients, 2]To develop postoperative care standards for nurses dealing with percutaneous nephrostomy tube patients 3]To identify percutaneous nephrostomy tube patient' needs Subjects and method: Descriptive exploratory study was utilized on a sample of 16 nurses, 14 physician and 30 patients aged from 18-65 years from both sexes. This study was conducted in the urology department at Assiut University Hospital. Tools: utilized for data collection were a] Questionnaire sheet. B] Observation checklist sheet. C] Postoperative basic nurses' competencies opinionnaire sheet. D] Patient assessment sheet. Results: showed that; half of nurses had poor knowledge regarding post operative nursing care standards for percutaneous nephrostomy tube patients. Nurses showed that inadequacy in their practice. The majority of physicians and nurses had agreed as regard the basic nursing competencies for postoperative percutaneous nephrostomy tube patients. Conclusion: percutaneous nephrostomy tube patients exposed to several complications. Improving nurses` knowledge and practice can favorable decrease the incidence of these complications. Recommendations: Nurses should be aware by postoperative complications and how to prevent them. Nurses in need for in-service training programs and refreshing courses to improve their knowledge which will reflect on their practice.
\end{abstract}

Keywords: post operative nursing care standards\& Percutaneous Nephrostomy tube.

\section{Introduction}

A nephrostomy is a tube that's used to drain urine from the kidney into a bag outside the body. It helps to relieve a retained of urine in the kidney, caused by obstruction. (Karim, 2010). A percutaneous nephrostomy tube $(\mathrm{PCN})$ is a small, soft tube. It placed across the skin to drain urine from the obstructed kidney. (Nariculam, 2011). A percutaneous nephrostomy tube (PCN) is one way to re-establish drainage. (Cirillo, 2012)

In USA from January 2006 to December 2011 about 1,220 patients had undergone percutaneous nephrostomy tube insertion. (Kumar, and Ganesamoni, 2012). The number of patients who subjected percutaneous nephrostomy tube during the period 2011-2012 admitted to urology department of Assiut university hospital was approximately 700 cases. (Assiut University hospital records, 2012)

Historically, in 1912, Hugh Hampton Young passed a paediatric cystoscope percutaneously into a massively hydronephrotic kidney. Willard Goodwin described percutaneous access and nephrostomies in 1955. In 1976, Fernström and Johansson performed a percutaneous nephrostomy specifically to remove a kidney stone. In 1979, Smith and colleagues, from the University of Minnesota, began to remove stones from the renal pelvis and the ureter through percutaneous nephrostomy tracts. In 1981, Alken and colleagues, who were working in Germany, removed stones through matured percutaneous tracts. (Hautmann, 2011)

Indications for percutaneous nephrostomy include; Diversion of urine associated with urinary obstruction secondary to calculi diversion of urine from the renal collecting system in an attempt to treat fistulas or leaks resulting from traumatic or iatrogenic injury, malignant or inflammatory diseases. Treatment of urinary tract obstruction related to pregnancy. Treatment of complications related to renal transplants. Access for interventions such as direct infusion of substances for dissolving stones, chemotherapy, and antibiotic or antifungal therapy. (Cirillo, 2012)

Complication is rare. But, no procedure is free of risk and possible complications include; bleeding, infection, damage to nearby organs and tissues, kidney function loss, blood clots, reaction to the anesthesia such as, light-headedness, low blood pressure, wheezing and pain. Postoperative complications may include: urine leakage around the catheter, slippage of the catheter, obstruction of the tube or hematuria. (Karim, 2010)

Standards of care and practice are written criteria for nursing care and practice that all professional nurses are expected to meet. 
Standard are used by health care agencies to provide guidelines for care provided and professional responsibilities. Standards have an important impact on quality of care, patient outcomes and the work force environment

(Grohar, 2011)

\section{Significance of the study}

In recent year, increased number of cases of urinary tract obstruction and thus have increased percutaneous nephrostomy tube, the patient with percutaneous nephrostomy tube needed a special nursing care to improve the patient's outcome. This study will be the first study in this geographical location which will help patient to develop nursing care standard for percutaneous nephrostomy tube.

\section{Aims of the study}

The aim of the study includes:

1) To assess nurses knowledge and practice for patients undergoing percutaneous nephrostomy tube. 2) To develop nursing care standards for patients undergoing percutaneous nephrostomy tube. 3) To identify percutaneous nephrostomy tube patient' need.

\section{Subjects and Methods}

\section{Research design}

The research design in this study was descriptive exploratory

\section{Setting}

This study was conducted in the urology department at Assiut urology and nephrology university hospital.

\section{Subjects}

A Sample of all available staff nurses (16) and physicians (14) working in urology department and who agreed to participate in the study and (30 patients) that had undergone percutaneous nephrostomy tube was selected according to the following criteria:

\section{Inclusion criteria}

Adult conscious patients.

Both sexes were included.

Tools of the study

Four tools of the study were utilized for data collection and include the following:

Tool I: Nurse`s knowledge questionnaire sheet This sheet was developed by the researcher based on current national and international literature to assess nurse's knowledge as regarding percutaneous nephrostomy tube and it includes two parts:

Part 1: Sociodemographic data for nurses as nurse's age, sex, marital status, qualification and years of experience, attended training course for urology and attended other training courses. It includes 7 items (Questions from 1 to 7)

Part (2) : Assessment of Nurses' knowledge a) Knowledge about anatomy and physiology of urinary system b) Knowledge about percutaneous nephrostomy tube c) Knowledge about post-operative nursing care for percutaneous nephrostomy patient.

\section{Scoring system}

The total number of questions was (26). The total scores were (50). Poor level: who obtained less than $50 \%$ (less than 25 degrees). Fair level: who obtained 50-70\% (25- 35 degrees). Good level: who obtained more than $70 \%$ ( more than 35 degrees)

Tool II: Nurse`s practice observation checklist sheet

Observation checklist was developed by the researcher based on reviewing of literature to assess nurse's practical aspects of the basic competencies related to percutaneous nephrostomy tube. It consists of the following items:

Immediate postoperative nursing care of $(\mathrm{PCN})$ patient which includes 12 steps.

Performing hand washing which includes 8 steps.

Assessing and monitoring vital sign (temperature, pulse, respiration and blood pressure) which includes 50 steps.

Wound care which includes 17 steps.

Instructions before discharge which include 15 steps; instructions about hand washing, surgical site care, fluid intake, managing pain ,position of the nephrostomy tube, change the urine bag and complications .

Irrigation of (PCN) includes 10 steps.

Removal of (PCN) includes 7 steps.

Scoring system

The total score of observation checklist sheet was 119 items; each item in checklist was scored as follows: Two degree for each step that is done correctly, one degree for each step done incorrectly and zero for step that is not done.

In adequate practice level: who obtained less than $(60 \%)$.

Adequate practice level who obtained above (60\%).

Tool III : Post-operative Basic nursing opinionnaire sheet for physicians and nurses (PCOS)

It was developed by the researcher based on current national and international literature in order to elicit opinions of two groups as regard to the basic nursing for post-operative percutaneous nephrostomy tube patients. This tool covered 7 major broad items. 


\section{Scoring system}

Competencies of care

Agree

score

Disagree

1

0

Tool IV: Patient's assessment needs sheet:

It was used to assess expected post operative complications that might develop among percutaneous nephrostomy tube patients admitted to urology department. The assessment sheet includes items and covers the following areas:-

Part (1): Sociodemographic data: patient's name, age, sex, marital status, occupation, level of education. It includes 6 items

Part (2): Assessment of patients needs

\section{Methods}

An official letter was issued from the Dean of the Faculty of Nursing to the Head of Urology Department soliciting the necessary approval to conduct the present research after explain the aim of the study to obtain their cooperation.

Content validity was established by panel of (5) expertises from medical and surgical nursing staff

A pilot study carried out in February 2014 to test the feasibility and practicability of the study tools on $10 \%$ of sample (2 nurses and 3 patients).

Data were collected from urology department at Assiut University Hospital during the period from April /2014 to August/2014

Each nurse and patient was informed with the purpose of the study participation is voluntary.

\section{Results}

Table (1): Distribution level of nurses' knowledge as regards percutaneous nephrostomy tube.

\begin{tabular}{|c|c|c|}
\hline Nurses' knowledge & No. & \% \\
\hline Poor $(<=50 \%)$ & 8 & 50.0 \\
\hline Fair (51\% to $70 \%)$ & 5 & 31.2 \\
\hline Good $(71 \%$ to $100 \%)$ & 3 & 18.8 \\
\hline Total & $\mathbf{1 6}$ & $\mathbf{1 0 0}$ \\
\hline
\end{tabular}

\section{Nurses' knowledge}

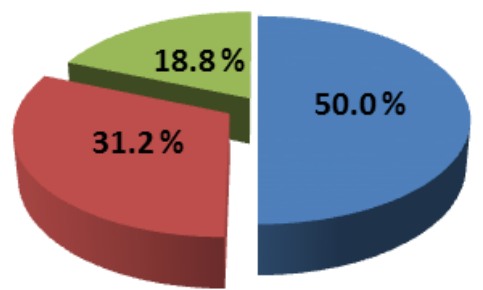

Poor

fair

Good

Table (2): Relationship between nurses' knowledge about percutaneous nephrostomy tube and Sociodemographic characteristics $(\mathrm{No}=16)$.

\begin{tabular}{|c|c|c|c|c|c|c|c|c|c|}
\hline \multirow{3}{*}{$\begin{array}{l}\text { Socio demographic } \\
\text { characters }\end{array}$} & \multicolumn{6}{|c|}{ Nurses' Knowledge } & \multirow{3}{*}{ Total No } & \multirow{3}{*}{ Mean \pm SD } & \multirow{3}{*}{ P-value } \\
\hline & \multicolumn{2}{|c|}{ Poor $(n=8)$} & \multicolumn{2}{|c|}{ Fair(n=5) } & \multicolumn{2}{|c|}{$\operatorname{Good}(n=3)$} & & & \\
\hline & No. & $\%$ & No. & $\%$ & No. & $\%$ & & & \\
\hline \multicolumn{9}{|l|}{ Gender } & \multirow{3}{*}{$0.074 *$} \\
\hline Male & 3 & 37.5 & 3 & 60 & 3 & 100.0 & (9) & $2.0 \pm 0.0$ & \\
\hline Female & 5 & 62.5 & 2 & 40 & 0 & 0.0 & (7) & $1.2 \pm 0.4$ & \\
\hline \multicolumn{9}{|l|}{ Age: (years) } & \multirow{4}{*}{0.133} \\
\hline$<20$ & 2 & 25 & 0 & 0.0 & 0 & 0.0 & (2) & $1.0 \pm 0.0$ & \\
\hline $20 \geq 30$ & 4 & 50 & 5 & 100.0 & 3 & 100.0 & (12) & $1.9 \pm 0.7$ & \\
\hline$>30$ & 2 & 25 & 0 & 0.0 & 0 & 0.0 & (2) & $1.0 \pm 0.0$ & \\
\hline
\end{tabular}




\begin{tabular}{|c|c|c|c|c|c|c|c|c|c|}
\hline \multirow{3}{*}{$\begin{array}{l}\text { Socio demographic } \\
\text { characters }\end{array}$} & \multicolumn{6}{|c|}{ Nurses' Knowledge } & \multirow{3}{*}{ Total No } & \multirow{3}{*}{ Mean \pm SD } & \multirow{3}{*}{ P-value } \\
\hline & \multicolumn{2}{|c|}{ Poor $(n=8)$} & \multicolumn{2}{|c|}{ Fair(n=5) } & \multicolumn{2}{|c|}{$\operatorname{Good}(n=3)$} & & & \\
\hline & No. & $\%$ & No. & $\%$ & No. & $\%$ & & & \\
\hline \multicolumn{9}{|l|}{ Marital status } & \multirow{4}{*}{0.111} \\
\hline Single & 2 & 25 & 2 & 40 & 3 & 100.0 & (7) & $2.1 \pm 0.8$ & \\
\hline Married & 5 & 62.5 & 3 & 60 & 0 & 0.0 & (8) & $1.3 \pm 0.5$ & \\
\hline Widowed & 1 & 12.5 & 0 & 0.0 & 0 & 0.0 & (1) & $1.6 \pm 0.7$ & \\
\hline \multicolumn{9}{|l|}{ Level of education } & \multirow{4}{*}{$0.022 *$} \\
\hline Diploma of nursing & 8 & 100.0 & 4 & 80 & 1 & 33.3 & (13) & $1.4 \pm 0.6$ & \\
\hline $\begin{array}{l}\text { Institute of Nursing } \\
\text { Technician }\end{array}$ & 0 & 0.0 & 1 & 20 & 0 & 0.0 & (1) & $2.0 \pm-$ & \\
\hline Bachelor of nursing & 0 & 0.0 & 0 & 0.0 & 2 & 66.7 & (2) & $3.0 \pm 0.0$ & \\
\hline \multicolumn{9}{|l|}{ Years of experience } & \multirow{4}{*}{0.113} \\
\hline$<5$ & 1 & 12.5 & 1 & 20 & 2 & 66.7 & (4) & $2.2 \pm 0.9$ & \\
\hline $5 \geq 10$ & 4 & 50 & 4 & 80 & 1 & 33.3 & (9) & $1.6 \pm 0.7$ & \\
\hline$>10$ & 3 & 37.5 & 0 & 0.0 & 0 & 0.0 & (3) & $1.0 \pm 0.0$ & \\
\hline \multicolumn{9}{|c|}{ Attended training course in urology } & \multirow{3}{*}{$0.037 *$} \\
\hline Yes & 5 & 62.5 & 1 & 20 & 0 & 0.0 & (6) & $1.1 \pm 0.4$ & \\
\hline No & 3 & 37.5 & 4 & 80 & 3 & 100.0 & (10) & $2.0 \pm 0.8$ & \\
\hline \multicolumn{9}{|c|}{ Attending other training courses } & \multirow{3}{*}{0.910} \\
\hline Yes & 3 & 37.5 & 3 & 60 & 1 & 33.3 & (7) & $1.7 \pm 0.7$ & \\
\hline No & 5 & 62.5 & 2 & 40 & 2 & 66.7 & (9) & $1.6 \pm 0.8$ & \\
\hline
\end{tabular}

Table (3): Distribution of Nurses` practice about care for patient with PCN.

\begin{tabular}{|c|c|c|c|c|c|c|c|c|}
\hline \multirow{3}{*}{ Items } & \multicolumn{4}{|c|}{ Done } & \multirow{2}{*}{\multicolumn{2}{|c|}{ ND }} & \multirow{2}{*}{\multicolumn{2}{|c|}{ NA }} \\
\hline & \multicolumn{2}{|c|}{$\mathbf{C}$} & \multicolumn{2}{|c|}{ I } & & & & \\
\hline & No & $\%$ & No & $\%$ & No & $\%$ & No & $\%$ \\
\hline \multicolumn{9}{|c|}{ 1-Ensure that infection control measures are properly followed in all procedure } \\
\hline \multicolumn{9}{|l|}{ _Hand washing: } \\
\hline a-With soap and water. & 1 & 6.2 & 6 & 37.5 & 9 & 56.3 & 0 & 0.0 \\
\hline b-With alcohol swab. & 0 & 0.0 & 0 & 0.0 & 16 & 100.0 & 0 & 0.0 \\
\hline \multicolumn{9}{|l|}{ 2- Post operative Nursing Care } \\
\hline Immediate postoperative care & 2 & 12.5 & 3 & 18.7 & 11 & 68.8 & 0 & 0.0 \\
\hline \multicolumn{9}{|c|}{ 3- Continuous patient monitoring and recording following surgery } \\
\hline A- Body temperature by axillary route. & 3 & 37.5 & 3 & 18.7 & 7 & 46.8 & 0 & 0.0 \\
\hline B-Pulse. & 0 & 0.0 & 0 & 0.0 & 16 & 100.0 & 0 & 0.0 \\
\hline C-Respiration. & 0 & 0.0 & 0 & 0.0 & 16 & 100.0 & 0 & 0.0 \\
\hline D- Blood pressure. & 1 & 6.2 & 2 & 12.5 & 13 & 81.4 & 0 & 0.0 \\
\hline E-Wound care. & 5 & 31.3 & 1 & 6.3 & 3 & 18.7 & 7 & 43.7 \\
\hline $\begin{array}{l}\text { 4- Health education for patients before } \\
\text { discharge }\end{array}$ & 6 & 37.5 & 1 & 6.2 & 9 & 56.3 & 0 & 0.0 \\
\hline 5- Irrigation of nephrostomy tube. & 0 & 0.0 & 0 & 0.0 & 0 & 0.0 & 16 & 100.0 \\
\hline 6- Nephrostomy tube removal. & 0 & 0.0 & 0 & 0.0 & 0 & 0.0 & 16 & 100.0 \\
\hline
\end{tabular}

$\begin{array}{llll}C=\text { Correct } & I=\text { Incorrect } & N D=\text { Not done } & N A=\text { Not applicable }\end{array}$ 
Table (4) : Opinions of physicians and nurses regarding post operative nursing care standards for patients undergoing percutaneous nephrostomy tube.

\begin{tabular}{|c|c|c|c|c|c|c|c|c|c|}
\hline \multirow{3}{*}{ skills } & \multicolumn{4}{|c|}{ Nurses (No. 16) } & \multicolumn{4}{|c|}{ Physicians (No. 14) } & \multirow{3}{*}{ P-value } \\
\hline & \multicolumn{2}{|c|}{ Agree } & \multicolumn{2}{|c|}{ Disagree } & \multicolumn{2}{|c|}{ Agree } & \multicolumn{2}{|c|}{ Disagree } & \\
\hline & No & $\%$ & No & $\%$ & No & $\%$ & No & $\%$ & \\
\hline $\begin{array}{l}\text { 1.The Urology Department } \\
\text { environment is ready to } \\
\text { receive the percutaneous } \\
\text { nephrostomy tube patient }\end{array}$ & 14 & 87.5 & 2 & 12.5 & 13 & 92.8 & 1 & 7.2 & 0.640 \\
\hline $\begin{array}{l}\text { 2.The urology Department } \\
\text { environment is safe to } \\
\text { receive percutaneous } \\
\text { nephrostomy tube patient }\end{array}$ & 15 & 93.7 & 1 & 6.3 & 13 & 92.8 & 1 & 7.2 & 0.925 \\
\hline $\begin{array}{l}\text { 3.Continuous monitoring and } \\
\text { recording are followed for } \\
\text { post-operative patients }\end{array}$ & 15 & 93.7 & 1 & 6.3 & 13 & 92.8 & 1 & 7.2 & 0.925 \\
\hline $\begin{array}{l}\text { 4.All infection control } \\
\text { measures are properly } \\
\text { followed in all procedures }\end{array}$ & 14 & 87.5 & 2 & 12.5 & 13 & 92.8 & 1 & 7.2 & 0.640 \\
\hline $\begin{array}{l}\text { 5.All health team are } \\
\text { properly attired for patient } \\
\text { care }\end{array}$ & 15 & 93.7 & 1 & 6.3 & 13 & 92.8 & 1 & 7.2 & 0.925 \\
\hline $\begin{array}{l}\text { 6. Safety for each patient } \\
\text { during transportation from } \\
\text { operating room to unit }\end{array}$ & 15 & 93.7 & 1 & 6.3 & 14 & 100.0 & 0 & 0.0 & 0.359 \\
\hline $\begin{array}{l}\text { 7. All staff (health team) } \\
\text { follow ethics and patients } \\
\text { rights in the urology } \\
\text { department }\end{array}$ & 15 & 93.7 & 1 & 6.3 & 14 & 100.0 & 0 & 0.0 & 0.359 \\
\hline
\end{tabular}

Table (5): Socio-demographic characteristics of the studied patients.

\begin{tabular}{|c|c|c|}
\hline Items & No. $(n=30)$ & $\%$ \\
\hline \multicolumn{3}{|l|}{ Age(years) } \\
\hline $18>40$ & 11 & 36.7 \\
\hline$>40-60$ & 10 & 33.3 \\
\hline$>60$ & 9 & 30.0 \\
\hline Mean \pm SD & \multicolumn{2}{|c|}{$45.4 \pm 1.5$} \\
\hline Sex & & \\
\hline Male & 18 & 60.0 \\
\hline Female & 12 & 40.0 \\
\hline \multicolumn{3}{|l|}{ Marital status } \\
\hline Single & 4 & 13.3 \\
\hline Married & 22 & 73.4 \\
\hline Divorced & 1 & 3.3 \\
\hline Widow or widower & 3 & 10.0 \\
\hline \multicolumn{3}{|l|}{ Level of education } \\
\hline High education & 3 & 10.0 \\
\hline Secondary school education & 1 & 3.3 \\
\hline Student & 4 & 13.3 \\
\hline Read and write & 6 & 20.1 \\
\hline Illiterate & 16 & 53.3 \\
\hline
\end{tabular}




\begin{tabular}{|c|c|c|}
\hline Items & No. $(n=30)$ & $\%$ \\
\hline \multicolumn{3}{|l|}{ Occupation } \\
\hline Employee & 3 & 10.0 \\
\hline Worker & 1 & 3.3 \\
\hline Farmer & 17 & 56.7 \\
\hline House wife & 6 & 20.0 \\
\hline Student & 3 & 10.0 \\
\hline
\end{tabular}

Table (6): Distribution of medical data about percutaneous nephrostomy tube of the studied patients.

\begin{tabular}{|l|c|c|}
\hline \multicolumn{1}{|c|}{ Items } & No. $(\mathbf{n}=\mathbf{3 0})$ & \% \\
\hline What is the reason for the installation of percutaneous nephrostomy tube \\
\hline 1. Infected hydronephrosis & 6 & 20 \\
\hline 2. Obstructive anuria & 13 & 43.3 \\
\hline 3. Dilated both kidneys, with renal impairment & 11 & 36.7 \\
\hline
\end{tabular}

Table (7) : Distribution of post-operative potential complications of the studied patients: $N=30$.

\begin{tabular}{|l|c|c|c|c|}
\hline \multirow{2}{*}{\multicolumn{1}{|c|}{ Items }} & \multicolumn{2}{c|}{ Present } & \multicolumn{2}{c|}{ Not present } \\
\cline { 2 - 5 } & No. & $\mathbf{\%}$ & No. & \% \\
\hline 1-Complications related to anesthesia & 6 & 20.0 & 24 & 80.0 \\
\hline 2-Hematuria & 13 & 43.3 & 17 & 56.7 \\
\hline 3-Obstruction of the tube & 9 & 30.0 & 21 & 70.0 \\
\hline 4-Dislodgement of the tube & 4 & 13.3 & 26 & 86.7 \\
\hline 5-Urine leak & 14 & 46.7 & 16 & 53.3 \\
\hline 6-Pain & 29 & 96.7 & 1 & 3.3 \\
\hline 7-Heamorrage & 0 & 00.0 & 30 & 100.0 \\
\hline 8-Skin infection & 5 & 16.7 & 25 & 83.3 \\
\hline 9-Kidney infection (fever-chills) & 9 & 30.0 & 21 & 70.0 \\
\hline 10-Bowel transgression and colonic injury & 0 & 0.0 & 30 & 100.0 \\
\hline 11-Injury to intra-abdominal viscera & 0 & 0.0 & 30 & 100.0 \\
\hline
\end{tabular}

Table (1): Distribution level of nurses' knowledge as regards percutaneous nephrostomy tube:

Reflected that; half of nurses (50.0\%) had poor level of knowledge as regarding percutaneous nephrostomy tube, $(31.2 \%)$ of nurses had fair level and $(18.8 \%)$ had good level.

Table (2): Relationship between nurses' knowledge about percutaneous nephrostomy tube and Sociodemographic characteristics: Showed that; there was a statistically significant difference between patients' knowledge about percutaneous nephrostomy tube and Patients' gender, level of education and attended training course in urology with $\mathrm{p}$-value $0.074,0.022$ and 0.037 respectively.

Table (3): Distribution of Nurses ` practice about care for patient with PCN: Shows that; all of nurses had not done hand washing with alcohol swab, monitoring of pulse and respiration practice.

Irrigation of nephrostomy tube and nephrostomy tube removal practices are not applicable with percentage of $100 \%$.

Table (4) : Nurses and physicians point of view about the nursing care standards for PCN: Shows that the vast majority of physicians and nurses agree with basic post operative nursing care standards

Table (5) : Socio-demographic characteristics of the studied patients: Cleared that; more than one third of patients (36.7\%) are (18>40 years old), $(60.0 \%)$ of patients are males, $(73.4 \%)$ of them were married, $(53.3 \%)$ are illiterate and $(56.7 \%)$ of them are farmers.

Table (6): Distribution of medical data about percutaneous nephrostomy tube of the studied patients: Illustrated that; more than one third of patients had obstructive anuria (43.3\%) and two thirds of patients had not been subjected to percutaneous nephrostomy tube before $(73.3 \%)$.

Table (7): Distribution of post-operative potential complications of the studied patients: Showed that; all patients had no hemorrhage, bowel 
transgression and colonic injury. On other hand the vast majority of patients had pain as post-operative complications.

\section{Discussion}

Based on the results of the present study, the majority of the nurses, ages ranged from 20- $<30$ years and have diploma of nursing. The majority of them have experience range from 5 to 10 years. Bahza (2013) is in the same line with the current study findings which revealed that the majority of nurses were married having nursing diploma. Most of them have an experience more than 3 years

In this present study, the minority of nurses has inservice training courses related to infection control and the majority of them have no in-service training courses related to urology. This is in agreement with Pancorbo-Hidalgo (2007), who stated that nurses' knowledge was affected by professional education and training. Mustafa (2012) goes in the same line with the current study findings as the minority of the nurses have in-service training courses related to infection control precautions.

As regard knowledges about percutaneous nephrostomy tube, half of nurses had poor level of knowledge as regarding percutaneous nephrostomy tube, $(31.2 \%)$ of nurses had fair level and (18.8\%) had good level. This result may be attributed to insufficient courses related to percutaneous nephrostomy tube included in their undergraduate curriculum of nursing education. Most nurses stated that their knowledge gained while working with patients. Also there is no arabic source for updating and continuing their education.

Based on the present study showed that the majority of nurses aging $<20$ and $>30$ years had poor level of knowledge about percutaneous nephrostomy tube. Bachelor nurses had good level of knowledge about percutaneous nephrostomy tube. Nurses with years of experience $>10$ years had poor level of knowledge about percutaneous nephrostomy tube. Nurses who attended training courses had good level of knowledge as regarding percutaneous nephrostomy tube.

The present study showed that poor knowledge was among the group having more than 10 years of experience. This might be due to that these groups of nurses are responsible for administrative and managerial activities. This finding was in accordance with Ali, (2010) who found that the highest mean score of practice is among younger nurses and those who have the least experience. The present study revealed that poor knowledge was among diploma nursing. This result disagrees with Gamal, (2005) \& Abolwafa, (2009) who found that good level of knowledge regarding universal infection control precautions was ‘attainedly those who have Bachelor in nursing.

The present study shows that; the majority of nurses don't perform immediate postoperative nursing care. Ahmed (2011) was in the same line with the current study which revealed that more than half of nurses don't perform immediate postoperative nursing care. The findings of the present study showed that; most of nurses' measure patient temperature only and neglect the other items of vital signs (pulse, respiration and blood pressure). This finding of the current study was disagreeing with Ahmed, (2013) who stated that half of nurses had done adequate vital signs measurement.

In the present study most of nurses don't perform wound care accurately. Some nurses believed that it is the responsibility of surgeon and on the other hand it is a part of the department policies. Ahmed, (2013) was in the same line with the results of the current study and found that only three of the studied nurses had done adequate wound care and dressing. Some nurses believed that is the responsibility of medical staff.

Regarding health education before discharge, nurses don't perform before discharge instructions because they believe that it the responsibility of the department physicians. This result was in the same line with Ahmed, (2011) who revealed that only a minority of nurses give inadequate instructions to patients before discharge.

The results of the present study revealed that, the majority of physicians and nurses at urology department of Assiut University Hospital agreed the environment of urology department is safe to receive the percutaneous nephrostomy tube patient. Murphy, (2011) agrees with the present study results and stated that recent attention in health care has been on the actual architectural design of a hospital facility, including its technology and equipment, and its effect on patient safety.

The findings of the present study showed that, the majority of nurses and physicians had agreed with continuous monitoring and recording for post operative percutaneous nephrostomy tube patients. Ponsky, (2005) mentioned that, postoperative care is the management of a patient after surgery. This includes care given during the immediate postoperative period, both in the operating room and post anesthesia care unit (PACU), as well as during the days following surgery.

The present study was carried out in 30 patients more than half of patients were males, mean age of studied patients was 45 years, these results agree with the study of Sood, et al., (2011); which revealed that; study was carried out in 32 patients suffering 
from obstructive uropathy. It included 18 males and 14 females. The mean age in this study group was 41.4 years. In the relation to material status it was found that the majority of patients were married this study finding was supported by Mohammed (2010), who found that; the majority of the patient study were married.

As regard medical data about patients, the most common cause for installation of percutaneous nephrostomy tube is obstructive anuria and one third of patients had not been subjected to percutaneous nephrostomy tuber before $(73.3 \%)$.

In this study more than half of patients had abnormal temperature at $4^{\text {th }}$ hours post operatively.

In this study patients had hematuria as a post operative complication. These results agree with the study of Karim (2010) which revealed that; 12/40 patients complained of macroscopic hematuria post percutaneous nephrostomy tube.

Also; in this study 9/30 patients had obstruction of the tube. Ahmed, and Pansota, (2014) revealed that; Post procedural blockage of the nephrostomy tube was observed in 9/50 of their study.

Also the present study illustrates that; the vast majority of patients had pain and kidney infection (fever-chills) as post-operative complications. Zhang and Chen, (2005) revealed that patients with urinary tract infection (UTI) should be treated with appropriate antibiotic therapy prior to percutaneous renal surgery because of the risk of infection.

\section{Conclusions}

Based on finding of this study, it can be concluded that

* Half of nurses had fair knowledge regarding post operative nursing care standards for patients undergoing percutaneous nephrostomy tube.

* Nurses showed inadequacy in their practice about post operative nursing care standards for patients undergoing percutaneous nephrostomy tube

* The majority of nurses had agreed as regarding; the basic nurse's for post operative percutaneous nephrostomy tube patients. This included 7 major items, which were further, subdivided into sub items

\section{Recommendations}

\section{For nurses}

$\checkmark$ Continuous nursing education and in-service training programs at urology department should be well organized within Assiut University Hospital and equipped with the necessary educational facilities and materials necessary to upgrade the knowledge and skills of practicing nurses, which will be reflected on better outcome and service for inpatients.

$\checkmark$ Nurses should be aware by postoperative complications, how to prevent them and how to deal with them when they develop.

$\checkmark$ Nurses should be aware by instructions that are given to patients before discharge and inform patients about them

\section{For patients}

$\checkmark$ Patients are to be provided with sufficient relevant written information to remind them about what they can or cannot do to assist them to cope with the treatment.

$\checkmark$ Patients are to be provided with sufficient information about signs and symptoms of the potential complications and the importance of seeking rapid medical advice.

For administration

$\checkmark$ Adequate supplies and facilities should be available in the unit.

$\checkmark$ Periodic monitoring of nurses knowledge and practice to evaluate the level of nurses.

\section{References}

1. Abolwafa N., (2009): Assessment of nurses' knowledge and performance related to infection control in the neonatal units at Elminia City Hospitals, M.D.thesis in Paediatric Nursing, Faculty of Nursing, Assiut University, pp. 95-97

2. Ahmad I., Pansota M., (2014): Comparison between double $\mathrm{J}$ (DJ) ureteral stenting and percutaneous nephrostomy $(\mathrm{PCN})$ in obstructive uropathy. Pak J Med Sci; 29(3):725-29.

3. Ahmed, A., (2013): Developing nursing care standards for patients post discectomy at Assiut University Hospital, thesis Submitted for Partial Fulfillment of the Master Degree in Medical Surgical Nursing, faculty of nursing. Assiut University, pp.67-69.

4. Ahmed, R., (2011): Developing Postoperative care standards for patients who had drainage of chronic subdural hematoma, thesis submitted for partial fulfillment of the requirements of the master degree in adult nursing, Faculty of nursing, Assiut University, p.102.

5. Ali M., (2010): Assessment of nurse's knowledge and performance related to universal infection control precautions at mallaway general hospital departments M.D. Thesis in adult nursing, Faculty of nursing, Assiut University, p.57.

6. Assiut university Hospital statistics records, (2011-2012)

7. Bahza, N., (2013): Developing Nursing Care Standards for Patient with Colostomy at Assiut 
University Hospital, thesis Submitted for Partial Fulfillment of the Requirements of The Master Degree in Medical Surgical Nursing (Adult Nursing), faculty of nursing. Assiut University, discussion part, pp.57-58.

8. Cirillo, J., (2012): percutaneous nephrostomy Available at:

http://www.drugs.com/cg/nephrostomy-tubeinsertion-after care-instruction.html

9. Gamal, L., (2005): Establishing standards for prevention of nosocomial infection in the recovery rooms and surgical ward at El-minia university Hospital M., Thesis in Adult Nursing, Faculty of Nursing, Assiut University,pp.84-85.

10. Grohar, M., (2011): Leadership and management in nursing, $4^{\text {th }}$ ed., Pearson company, chap 9, p.182.

11. Hautmann, S., (2011): nephrostomy. Available at: http://emedicine.Medscape. Com/article/445893-overview.

12. Karim, R., (2010): Percutaneous nephrostomy by direct puncture technique: an observational study Indian, Nephrol pp 84-88.

13. Kumar, S., \& Ganesamoni, R., (2012): Fragmented Pigital percutaneous Nephrostomy Tube: Etiology and Management, Korean Journal of Urology, pp 492-496. Available at: http://KJ Urology. Org.

14. Mohammed, S., (2010): Effect of rehabilitation program for patients undergoing hemodialysis upon their psychosocial adjustment, M.S. thesis in medical- surgical nursing, Faculty of Nursing, Assiut University.

15. Murphy, M., (2011): The Impact of Facility Design on Patient Safety, an Evidence-Based Handbook for Nurses. Accessed at www.healthdesign.org/research/reports/physical _environ.php.

16. Mustafa, N., (2012): Developing standards of post-operative nursing interventions for lower limb amputated patients, M.S. thesis in Adult Nursing (Medical - Surgical Nursing), Faculty of Nursing, Assiut University, pp.75-78.

17. Nariculam, J., (2011): Nephrostomy insertion for patients with bilateral ureteric obstruction The British Journal of Radiology.0:38306763 v1.

18. Pancorbo-Hidalgo, P., (2007): Pressure ulcer care in Spain nurses' knowledge and clinical practice, Journal of Advanced Nursing, 58, (4), pp.327-338.

19. Ponsky, M., (2005): The Cleveland Clinic Guide to Surgical Patient Management, 1st ed. Philadelphia: Mosby,

20. Sood G., Sood A, Jindal A., Verma D., Dhiman D., (2011): Ultrasound guided percutaneous nephrostomy for obstructive uropathy in benign and malignant diseases. Int Braz J Urol; 32:281-6.

21. Zhang X., \& Chen Z., (2005): Comparison of open surgery versus retroperitoneoscopic approach to chyluria. J Urol; 169: 991-993. 